\title{
EL PLURAL LEgado FiLOSÓfico DE ARANGUREN ${ }^{1}$
}

\author{
Carlos GOMEZ SÁNCHEZ \\ UNED
}

Es muy difícil reducir a la obediencia a quien no aspira a mandar (J.-J. ROUSSEAU, Discurso sobre la desigualdad entre los hombres)

Comenzamos ahora nuestro curso sobre el plural legado filosófico de José Luis López Aranguren, en el que nos detendremos a lo largo de esta semana. El que se desarrolle precisamente en Avila fue un particular empeño. Nos parecía que era uno de los marcos más adecuados, dado que ésta fue su tierra natal y la tierra que le acoge desde que, en abril de hace ya dos años, Aranguren nos dijo definitivamente adiós. El participó también en diversas ocasiones en estos cursos de verano de la Universidad a Distancia, y en uno de los últimos que lo hizo me cupo el honor de presentarle. En el actual, quiero empezar dando las gracias a los profesores invitados, por su interés y disponibilidad en hacerlo; a ustedes, por su asistencia y participación, y, de manera muy especial, a algunos de los hijos del profesor Aranguren que nos acompanan. Todos ellos muestran que el adiós al que me refería no equivale a olvido. Este mismo curso es una forma de reconocimiento - la que hoy nos es factible-, evocando la figura del maestro y del amigo y estudiando su obra, el plural impulso que nos dejó.

1 El presente texto fue leído en la presentación del curso El plural legado filosífico de José Luis López Aranguren, celebrado en Avila en julio de 1.998, en el marco de los IX cursos de verano de la UNED. Agradezco su participación en el mismo a los profesores Elías Díaz, Manuel Fraijó, Antonio Garcia-Santesmases, José M. ${ }^{2}$ González, Manuel Reyes Mate, Javier Muguerza, Roberto Rodríguez Aramayo, Javier San Martín, Fernando Savater y Carlos Thiebaut. Y a los alumnos, su activa asistencia y su cordialidad.

ENDOXA: Series Filosfficas, n. ${ }^{\circ} 12,2000$, pp. 341-358. UNED, Madrid 
Para las jóvenes generaciones quizá sea difícil hacerse cargo de las circunstancias en las que Aranguren hubo de desenvolverse. Y, sin embargo, sin tener en cuenta la situación de la que partíamos no puede enjuiciarse adecuadamente su contribución a la filosofía española. Voy a evocar, pues, brevemente, antes de centrarme en el pensamiento de Aranguren, esa circunstancia y algunos rasgos significativos de la historia que nos condujo hasta allí. Pero no teman que haya de remontarme tan lejos como para tener que hablar de mis paisanos cordobeses Séneca, Averroes o Maimónides u otros ilustres jalones de lo que, un tanto abusivamente tal vez, cupiera llamar pensamiento español o pensamiento ibérico. Bastará, en cambio, con tomar nota del repliegue que, a partir de la segunda mitad del siglo XVI, España conoció, apartándola del hilo fundamental de desarrollo del pensamiento científico y filosófico, producido en la Europa moderna. $\mathrm{Y}$ aunque se pueden introducir matices en ese juicio, como efectivamente lo han hecho hispanistas de la talla de J. Sarrailh en La España ilustrada de la segunda mitad del siglo XVIII o R. Herr en España y la revolución del siglo $X V I I I$, lo cierto es que podemos suscribir el trazo fundamental de tal argumentación, al menos por lo que a lo exangüe de la Ilustración española se refiere. Un apartamiento y fragilidad que cuando se perdieran los últimos restos del imperio colonial español, en 1.898 , iba a ser tema de reflexión de una generación que unió su rótulo denominador a esa fecha.

Por lo que al tiempo inmediatamente anterior se refiere, el tono general de la actividad filosófica en nuestro país, puede ofrecerlo el informe que el profesor polaco Wincenty Lutoslawski redactó para la recién fundada revista KantStudien, a propósito del conocimiento de la filosofia kantiana en España ${ }^{2}$. Sus pesquisas fueron tan decepcionantes, como para concluir diciendo que Kant ist in Spanien so gut wie gänzlich unbekannt, algo así como que sobre Kant reina-

2 Sobre las peripecias de ese informe, cf. J. M. PALACios, "La filosofía de Kant en la Espafía del siglo XIX", en J. Muguerza y R. RodrIGUez Aramayo (eds.), Kant después de Kant. En el bicentenario de la "Critica de la razón práctica", Madrid, Tecnos, 1.989, 673-707. Al marco histórico-filosófico que estamos apuntando se refiere Javier MUGUERZA en «El presente de la filosofía en Españam, Revista de Occidente, 122-123 (1.991), 65-82. Cf. asimismo, J. L. ABELLÁN, Historia critica del pensamiento español (especialmente, vol. V, 1, 2 y 3), Madrid, Espasa, 1.9891.991. (Una versión resumida, "De Séneca a nuestros días", en Historia del pensamiento españoh Madrid, Espasa, 1.996); V. CACHO VIU, La Institución Libre de Enseñanza, Madrid, Rialp, 1.962; E. DIAZ, Pensamiento español, 1.939-1.975, Madrid, Tecnos, 1.983; A. GuY, Histoire de la philosophie espagnole, Toulouse, Univ. de Toulouse-Le Mirail, 1.983 (trad. de A. Sánchez, en Barcelona, Anthropos, 1.985). 
ba en España una ignorancia sin fisuras. Es cierto que la Critica de la Razón Pura había sido traducida parcialmente con anterioridad y el neokantismo hacía acto de presencia en algún pequeño círculo, pero el citado informe es revelador del secular apartamiento de España de la Europa moderna, pues no en mejores circunstancias se encontraban otras corrientes y autores.

Con todo, y como decía, la situación iba a cambiar de manera notable en poco tiempo. La importación de la filosofía del idealismo alemán - aunque fuera a través de esa figura secundaria suya que es F. Krause-, por parte de Julián Sanz del Río, dio lugar al desarrollo de ese peculiar movimiento que se ha denominado el krausismo español, influyente en la posterior Institución Libre de Enseñanza, que, si no dio figuras filosóficas de relieve, vino a actuar de casa-madre, en torno a la que se fraguarían las obras de poetas o artistas de la talla de Lorca, Dalí o Luis Buñuel. Y los hombres de la generación del 98 se abrirían progresivamente a la filosofía clásica y buena parte del pensamiento europeo de la época, como es el caso sobre todo de Unamuno, no sólo familiarizado con Kant, sino asimismo conocedor de algunas corrientes del socialismo y el positivismo, de Schopenhauer y Nietzsche (también cultivados, entre otros, por Baroja) y avisado lector de Soren Kierkegaard en el original danés.

Es, sin embargo, la empresa modernizadora de Ortega la que elevó el listón filosófico de manera considerable. Convencido de que «España era el problema y Europa la solución", no sólo se convirtió en un buen conocedor de Kant - tras su permanencia en Marburgo con los neokantianos Hermann Cohen y Paul Natorp- y, más tarde, en uno de sus más decididos críticos, sino que asimismo incorporó España al pensamiento científico y filosófico de la época con un rigor y perspicacia verdaderamente notables. En la editorial Revista de Occidente, o en la revista del mismo nombre que fundó, daba a conocer las principales discusiones de la filosofía europea con diligente puntualidad, particularmente por lo que se refiere a las obras de inspiración fenomenológica (del propio Husserl a Max Scheler), pero dialogando también con el historicismo de Dilthey, el existencialismo de Heidegger o el psicoanálisis de Freud. Ortega, por aquel entonces, no actuaba sólo y la Facultad de Filosofía de la Universidad de Madrid (con profesores como José Gaos, Manuel García Morente o Xavier Zubiri) alcanzó un nivel perfectamente equiparable al de las mejores europeas, aunque la caja de resonancia en la que se desenvolvía permitiera una amplificación menor. La caja, por supuesto, era la propia España, un país deficientemente incorporado a la industrialización 
y carente de la vigorosa clase media que había protagonizado las revoluciones burguesas europeas, al que Ortega todavía consideraba, en el prólogo de una de sus mejores obras, Meditaciones del Quijote, de 1.914, una tierra de infieles por lo que al cultivo de la filosofia se refiere. Esa Espana, convertida por los noventayochistas en tema de amarga meditación, que aún le hacía interrogarse patéticamente a Ortega en esa misma obra: «bajo la frialdad inmensa y cósmica del parpadeo astral, ¿qué es esta España, este promontorio espiritual de Europa, esta como proa del alma continental?" ${ }^{3}$. Pero, como hemos visto, proa del alma o promontorio espiritual, el caso es que, de lo que se trataba, shabiendo negado una España", era de hallar otra y ese upaso honroso" parecía iba a poderse cumplir 4 .

La guerra civil truncó, sin embargo, semejante desarrollo. Sin reparar ahora en otros aspectos, el nuevo régimen, con su desprecio hacia los intelectuales, forzó el exilio de lo mejor del pensamiento español ${ }^{5}$. Muchos de ellos (José Gaos, Juan David García Bacca, Eugenio Imaz, Eduardo Nicol, Adolfo Sánchez Vázquez, Joaquín y Ramón Xirau, María Zambrano) fueron acogidos y se integraron en Universidades hispanoamericanas. Otros (Julián Marías, Xavier Zubiri), aun permaneciendo en España, vivieron en el exilio interior, sin poder acceder a puestos universitarios, como tampoco lo hizo Ortega, cuando decidió volver y encontró un país de uuna salud insultante». Los insultos provenían, en parte, de los medios académicos oficiales donde se había instalado entretanto una escolástica recolada, promovida por la dictadura al rango de filosofía oficial del nacionalcatolicismo, que era la que todavía se impartía cuando mi generación comenzó sus estudios universitarios en un año tan emblemático como el de 1.968. Pero, para entonces, muchas cosas habían empezado a cambiar. Por lo que a la filosofía y, en concreto, a la ética se refiere, el cambio decisivo había venido de la mano de José Luis López Aranguren.

3 J. Ortega y Gasset, Meditaciones del Quijote, ed. de J. Marías, 2. ed., Madrid, Cátedra, $1.990,168$.

4 Ibid., 89.

5 Cf. J. L. ABELlAN, Filosofia española en América (1.936-1.966), Madrid, Guadarrama, 1.966; El exilio filosófico en América. Los transterrados de 1.936, México, FCE, 1.998. A la necesidad de recuperar el diálogo con el exilio filosófico se refirió tempranamente J. L. L. ARANGUREN en su artículo de 1.953 "La evolución espiritual de los intelectuales españoles en la emigración", recogido en Critica y meditación (Madrid, Taurus, 1.957) y, en la actualidad, en sus Obras completas. VI, ed. de F. Blázquez, Madrid, Trotta, 1.997, 108-140. 
En el recuerdo que le ha dedicado a Aranguren, con motivo de su fallecimiento, en el número-homenaje de la revista Isegoría el psiquiatra cordobés Carlos Castilla del Pino nos ha dejado un hermoso testimonio, del que quiero reproducir algunos párrafos:

"Dejé de ser católico -comienza diciendo Carlos Castilla del Pino- hacia los catorce o quince años, cuando el catolicismo era socialmente imprescindible. Impregnaba todo el medio social español y, sin contención alguna, se introducfa impertinente, hasta en la privacidad. En España - hablo de los años cuarenta y hasta los sesenta - había que tomar posición respecto del catolicismo y el católico. El socialcatolicismo, el poder católico, era el poder. Un catolicismo ñońo, cursi, blando en apariencia, pero despiadado hasta la crueldad llegado el caso (y llegaba a las primeras de cambio) [...]. Buena parte de las energias de muchos españoles se consumían en la tarea de ser anticatólico. A diferencia del de entonces, el catolicismo de ahora no es el poder, sino un poder - y en franco declive- [...]. Aquel catolicismo al que repudiaba con todas mis fuerzas era el catolicismo espanol, estrictamente vaticanista. En Francia las cosas podian ser diferentes, cuando menos en amplios sectores. Aquellos volúmenes de Cristianismo y Mundo Moderno de Moeller; los Erudes Carmelitaines, los libros de Maritain, Bernanos, Mauriac, los de Mounier y muchos otros. También en Alemania, los de Scheler, los de Romano Guardini... De pronto, pero aquí, apareció Catolicismo dia tras dia de José Luis López Aranguren [1.955]. Un libro transparente, un libro culto, moderno, inusual para ser de un católico español [...]. En él, además, la cultura era la forma de apertura a otros mundos distintos al estrictamente católico. A aquel católico que había tras Catolicismo se le podía escuchar y se le podía leer. Se podía ir con él hasta el límite, que no teníamos derecho a sobrepasar, de su pensar y sentir lo religioso. Si su catolicismo era suyo, también reconocía el carácter de íntimo de la religiosidad (o no religiosidad) de su interlocutor, y era, por parte de él, respetado. [...]. El libro suscitó una reacción tan violenta en los medios católicos más ortodoxos como para que no pudiéramos desatenderlo de ninguna manera [...]. A medida que Aranguren era objeto de sospecha y perdía el respeto de la ortodoxia, se lo prestábamos los agnósticos y, desde luego, los heterodoxos" ${ }^{6}$.

6 C. Castilla Del Pino, «Recuerdo de José Luis L. Aranguren», Isegoria, 15 (1.997), 39 41 , cit. 39-40. 
Con todo, y por importante que fuera, al propio Aranguren le pareció después tímido y lo rehizo en su Contralectura del catolicismo (1.978). El interés por el fenómeno religioso fue, en efecto, el primer eje de su producción, cronológicamente hablando, y el primero al que dedicaremos nuestra atención. Resulta curioso que, en muchas ocasiones, los medios de comunicación olvidaran ese aspecto cardinal de la obra de Aranguren. El dia de su fallecimiento, TVE emitió una larga entrevista que, no mucho tiempo antes, había mantenido con Fernando Delgado, sorprendido de lo que denominaba catolicismo a machamartillo" de Aranguren, por más que su religiosidad estuviese muy alejada de la de D. Marcelino Menéndez Pelayo, a quien, como se sabe, se debe la expresión. Como Antonio García-Santesmases ha subrayado alguna vez ${ }^{7}$, esa actitud reflejaba la curiosidad con la que determinado pensamiento, supuestamente progresista, trataba de encajar un dato que no cuadraba en su imagen de Aranguren. Para muchos, si no para la mayoría, su imagen se vinculaba con el antifranquista valeroso, que llegó a perder su cátedra por enfrentarse a la dictadura; con el intelectual vigilante de la vida ética, social y política de su tiempo. Aranguren fue todo eso, pero sin renunciar en ningún momento a una profunda religiosidad, que le acompañó a la largo de toda su vida. Incluso en su etapa americana, cuando la época del forzado exilio en la Universidad de California, seguía puntualmente las publicaciones y acontecimientos que en ese ámbito se producían, fuera y dentro de nuestras fronteras. Y, tras el restablecimiento de la democracia, presidió, junto a José Gómez Caffarena, el Foro del Hecho Religioso, que se celebra anualmente en Madrid, como espacio de discusión multidisciplinar entre creyentes y agnósticos de muy diversos tipos, unidos por el común denominador de un talante abierto y dialogal, tal como el propio Aranguren reflejaba en la crónica del mismo que cada año ofrecía en las páginas del diario El Pais.

En un país como el nuestro, en el que la cultura religiosa -o mejor, la incultura - ha dado - y, en cierta medida, sigue dando- abundante pasto a todo el que ansíe algún género de receta, a un variado espectro de actitudes agavilladas por su común simplicidad, Aranguren, de talante, como decíamos, profundamente religioso, opuso a ellas su cristianismo heterodoxo, esto es, de otra opinión respecto a las instancias autoritarias - de variado signo-

7 A. Garcla-Santesmases, "José Luis Aranguren: cristiano heterodoxo", A Distancia, otono de 1.997, pp. XXIX-XXXI de los Cuadernos de cultura. 
, siempre más ardientes en la búsqueda de fórmulas que encapsulen el tema que preocupadas en plantearlo. De ahí su interés por el protestantismo, por Lutero, por Kierkegaard, por la teología de Karl Barth y sus sucesores y, entre nosotros, por Unamuno; su interés por el diálogo con las corrientes derivadas de la Ilustración y los movimientos políticos y sociales que, a veces, han vehiculado, $y$, a la postre, su inconformismo con esas etiquetas que más que distinciones oportunas buscan, por decirlo unamunianamente, un mote -católico, protestante, agnóstico, místico, ateo, racionalista-, cuyo claro significado se desconoce, pero en el que descansa el espíritu en su pereza ${ }^{8}$. Más eclesial que eclesiástico-institucional, Aranguren, sin renunciar a sus convicciones para abandonarse a un cómodo irenismo, rechazó el tono dogmático - no sólo el de la Iglesia oficial, tan torpe, por lo demás, por no decir injusta, con su figura, sino asimismo el de otros sectores, aunque fueran de signo inverso-, tono dogmático que, como ya advirtiera Rousseau, sno conviene sino a los charlatanes" " $\mathrm{y}$, frente al cual, parece haber hecho suyo el hermoso consejo que se puede leer en el Fedón, según el cual acerca de estos temas hay que lograr una de estas cosas: o aprender de otro cómo son, o descubrirlos por nosotros mismos, y, si nada de ello resulta posible, tomar la explicación mejor y más difícil de refutar de entre las humanas y embarcarse en ella como sobre una balsa para surcar navegando la existencia” ${ }^{10}$. Una navegación en la que José Luis Aranguren supo conjugar la cautela intelectual y la conciencia de los aspectos sombríos y sin sentido de la existencia con una disposición de confianza y ánimo, por la que, sin volver la vista ante el absurdo y el mal, evitaba quedar varado en ellos. Tal y como declaró al cerrar una larga entrevista biográfica concedida a Televisión Española en el programa «emblanzas», a la sombra de las murallas de Avila, con un tono nietzscheano que no solía ser habitual en él: «Pese a todo, yo me pregunto: ¿y esto es la vida?. Pues que vuelva otra vez".

Pero quizá su obra más importante desde el punto de vista de la filosofía de la religión -y por la que él mismo sentía predilección, según manifestó en las Primeras Conferencias Aranguren, celebradas en la Residencia de Estudiantes de

8 M. de UnAmUno, "Mi religión" (1.907), en Mi religión y otros ensayos, 6." ed., Madrid, Espasa-Calpe, 1.973, 9-15, cit. 11 .

9 J.-J. RouSSEAU, Las ensoñaciones del paseante solitario, ed. de F. J. Hernández, trad. de C. Ortega Bayón, Madrid, Cátedra, 1.986, 68.

10 Platón, Fedón, ed. de C. García Gual, en Diálogos. III, Madrid, Gredos, 1.986, 81. 
Madrid - fuese Catolicismo y protestantismo como formas de existencia (1.952), en donde la apertura al protestantismo no le impedía reivindicar algunos aspectos del talante católico, en particular por lo que se refiere a no ver en la angustia y la desesperación, por humanas que puedan ser, las únicas vías de acceso a lo religioso, o las vías por excelencia, pues, junto a ellas, también cabía hablar de diversas formas de plenitud y de paz -en medio de las zozobras y desgarros que, con frecuencia indeseada pero persistente, acechan el desarrollo de toda vida humana y amenazan devolverla a la barbarie- e incluso de una ética del contentom, a no confundir con un fácil optimismo ciego ante el mal, sino, más bien, tono moral que le hace frente, procurando no quedar atrapado en su red.

Como intelectual y filósofo, Aranguren era consciente de las dificultades racionales que la afirmación religiosa entraña, pues, sin tener que ir contra la propia razón, desborda, desde luego, sus posibilidades, por lo que, sea cual fuere la posición que al respecto se adopte, todas son, como lo quería Kant, asunto de la razón práctica, que no puede pretender agotar el tema racionalmente, sino tan sólo postularlo o decidirlo del modo que a cada cual le parezca más razonable. Esa imbricación de cautela intelectual y decisión práctica, de sobriedad filosófica y razonable esperanza, se ponen bien de manifiesto en una de las últimas declaraciones que hizo sobre la cuestión y a la que, para concluir este apartado, me quiero referir. Aranguren partía ahi de un tema que le era muy querido y que ya había tratado en otras ocasiones: el de la analogía entre la vida y la literatura, que permite contemplar nuestras vidas como textos, pues

"Todos y cada uno de nosotros - añadía - somos eso, textos vivos. Textos que nuestro 'yo reflexivo' va, por así decirlo, escribiendo, contándose a sí mismo, con más o menos tino, al hilo de la vida protagonizada por nuestro 'yo ejecutivo'. Contar es como vivir y vivir es como contar o, mejor dicho, contarse, de manera que el mundo vivido y el narrado se solapan inevitablemente. Somos o, al menos, nos figuramos ser nuestra propia novela, la 'narración narrante' de nuestra vida. Y, como los textos literarios, también los textos que somos requieren de interpretación, razón por la que todos aventuramos, clara o confusamente, nuestra propia hermenéutica. Como también cabe de ellos la exégesis que hagan los demás, si la llegan a hacer, cuando el relato se dé por concluido y nos toque, después de nosotros mismos, la hora de su 'comprensión'. ¿A quien pedir esta última comprensión que consista no tanto en juzgarnos cuanto en decirnos quiénes somos, quién 
soy?. No sé, tal vez a la Deidad ante la cual hayamos existido, siquiera como sueño, de suerte que, si 'la vida es sueño', sea, haya sido, esté siendo, vaya a ser sueño 'de' Dios. Pero ya digo que no sén" ".

Dejemos aquí, con esta estremecida esperanza, lo que habíamos denominado el eje religioso de Aranguren, para atender a otros aspectos de su producción. En efecto, por constante que fuera su atención a los temas de filosofía de la religión, su labor no se redujo a ese campo, sino que se amplió a muchos otros $y$, por lo pronto y muy principalmente, a la ética, que, según veremos, tiene mucho que ver con ese hacerse como un texto, al que acabamos de aludir. En el ámbito de la filosoffa moral, Aranguren supo enraizarse en las sugerencias y elaboraciones que autores como Ortega o Zubiri habían hecho al respecto. Por lo que a Ortega se refiere, escribió, en un momento en que se pretendía condenar sus escritos, un valiente y valioso estudio sobre la ética implícita en ellos, La ética de Ortega (1.958), que se sumaba a la reivindicación hecha por Julián Marías y Pedro Laín Entralgo. Aranguren también ha reconocido lo que debe al magisterio de Zubiri, cuyos cursos privados —algunos de los cuales han sido mucho más tarde publicados- pudo seguir. Pero fue Aranguren quien tematizó expresamente ese dominio en el pensamiento español. Su Etica apareció en 1.958, tres años despúes de haber obtenido una cátedra de Etica y Sociología en la Universidad de Madrid. Es una ética de inspiración reconocidamente aristotélica, pero con un Aristóteles y un Santo Tomás leídos a la altura de nuestro presente y no simplemente esclerotizados en fórmulas rutinarias. Y junto a ellos se hacía presente la filosofía moderna, bien a través del diálogo crítico con Kant, bien a través del pensamiento existencial de Kierkegaard, Heidegger o Sartre, además de las frecuentes referencias a la ética de los valores de Scheler, a la filosofía analítica (Moore, Wittgenstein, Ayer, Stevenson, Toulmin,...) y a la literatura, que tendía un puente entre la ethica docens, la ética en cuanto disciplina académica, y la ethica utens o moral vivida.

11 J. Muguerza, "Del aprendizaje al magisterio de la insumisión. (Encuentro con José Luis L. Aranguren)", en E. LOPEZ-ARANGUREN, J. MUgUeRZA, J. M.a VAlVERDE, Retraro de José Luis L. Aranguren, Barcelona, Círculo de Lectores-Galaxia Gutenberg, 1.993, 65-88, cit., 88. 
Aunque el influjo de Zubiri le hacía subordinar en esa obra la ética a la metafísica, con posterioridad la impronta kantiana se fue haciendo más patente, de modo que no iba a ser ya la metafísica la que sustentara a la ética, sino que, en todo caso, sería la ética la que podía dar paso a una problemática metafísica y a una apertura a la religión, al menos en forma de pregunta y como horizonte de problemas de los que la ética misma no se podía desentender. El abandono de una fundamentación metafísica no inclinó, pues, la balanza hacia el positivismo, ni hacia un escepticismo que no sólo negara la posibilidad de responder, sino incluso la legitimidad del preguntar. Y es que - según indicaba en la amplia entrevista que mantuvo a comienzos de nuestra década con Javier Muguerza, retomando un tema de su libro La comunicación humana (1.965) - , por contrarios que puedan parecer, el metafísico, que cree tener respuesta para todas las preguntas, y el escéptico, en la medida en que niega la legitimidad de todas aquellas preguntas para las que no encontramos respuesta, vendrian a darse la mano en la común actitud de prohibir el cuestionamiento: como cuando se pretende sostener que la pregunta por el sentido de nuestra vida es una pregunta sinsentido, pues nunca encontrará solución definitiva ${ }^{12}$. Pero ya Kant advirtió que es totalmente antifilosófico renunciar a las preguntas para las que no encontramos respuesta, pues, independientemente de que seamos, en efecto, capaces de responderlas o no, el caso es que la razón humana avanza inconteniblemente hacia ellas, sin que sea sólo la vanidad de saber mucho quien la mueve a hacerlo, sino más bien la propia inquietud humana, que haríamos mal en sofocar, relegándola al sótano de los trastos, con lo que no haríamos otra cosa que abdicar de nuestra fronteriza - pero, tal vez, también hermosa - condición. En esa línea, para Aranguren, la filosofía consistirá más en la capacidad de interrogación que en las posibles soluciones (siempre provisionales) que logremos alcanzar.

Y así, será en la antropología, más que en la metafísica, donde se busque el surgimiento de la moral, en cuanto que la vida humana (a diferencia de la del animal, básicamente acoplado a su entorno) es susceptible de multitud de recreaciones culturales, sin que las disposiciones biológicas nos fuercen estrictamente a ninguna de ellas, excepto la de forzarnos a elegir, que es a lo que se referían Ortega, al entender la vida humana como quehacer, Zubiri, al hablar de la moral como estructura, o Sartre, al pensar que estamos condenados a la

$12 \quad$ Ibid., 87-88. 
libertad. La vida humana es forzosamente moral, en el sentido, al menos, de que, aunque nos ha sido dada, no nos ha sido dada hecha, sino que cada cual ha de hacer la suya, ser el novelista —más o menos original o plagiario- de su propia vida. Desde este punto de vista, la amoralidad es imposible, un caso patológico o un concepto vacío. Todos somos necesariamente morales, por cuanto vivir la vida humana requiere no estar bajos de moral, no estar desmoralizados, sino con el suficiente ánimo como para acoger y afrontar las posibilidades y resistencias que ella nos ofrece. Claro que uno puede ser, hasta cierto punto al menos, responsable de su propia desmoralización o de su buen tono vital. Pero, en principio, estar alto de moral no equivale todavía a obrar bien y hay casos en que el malvado se levanta con la moral muy alta dispuesto a cometer su fechoría. Si en el plano de la moral como estructura, el término moral se contrapone ante todo a "desmoralizado", en el plano de la moral como contenido, moral se contrapone, en cambio, a inmoral». Y es que el humano quehacer, estructuralmente moral, puede luego desarrollarse de acuerdo a pautas morales o inmorales, debidas o indebidas. Contenidos de la moral que suelen venir ofrecidos sociohistóricamente por las diversas culturas, religiones o visiones de sentido y que cada cual habrá de elaborar desde su propia perspectiva. Esta dimensión, insoslayablemente individual, de la tarea ética fue progresivamente acentuada por Aranguren, al subrayar (así en su obra Lo que sabemos de moral - 1.967-, reeditada más tarde bajo el título de Propuestas morales, 1.983), junto a las dimensiones de la moral como estructura y la moral como contenido, la importancia de otra a la que calificó de moral como actituch pivotando sobre la autonomía de la conciencia, todo lo condicionada que se quiera, pero instancia última e irrebasable de la moralidad, que viene a aproximarse de este modo al propio esfuerzo por ser moral, esto es, a la kantiana "buena voluntad". Individualismo ético, que no es equivalente, ni mucho menos, para Aranguren, de ese individualismo rapaz, posesivo e insolidario tantas veces pregonado. Pues el que nuestras decisiones morales hayan de ser siempre, en definitiva, solitarias no quiere decir que hayan de ser insolidarias.

Precisamente de la dimensión social de la moral se ocuparía Aranguren en otra de sus obras más notables, Etica y Política (1.963), abriéndose a lo que el profesor Enrique Bonete, en su estudio Aranguren: la ética entre la religión y la 
politica ${ }^{13}$, ha destacado como la otra vertiente cardinal del pensamiento de Aranguren. $\mathrm{La}$ ética es siempre individual en el sentido de que el individuo es su base, su agente insustituible. Pero ese individualismo ético sólo puede realizarse en la apertura a los otros, bien sea que se relacione con ellos como otros concretos y personalizados —dando lugar a lo que podría denominarse ética de las relaciones interpersonales-, bien aparezcan en su horizonte como esos otros sin nombre determinado, desconocidos personalmente, pero respecto a los que está obligado en las tareas sociales de las que habría de ocuparse la ética social. El temple de Aranguren era más ético y religioso que político, pero, cada vez más, ese mismo temple le condujo a interesarse por las realidades político-sociales de su tiempo, sin llevar a cabo nunca una actividad propiamente política, mas sin desdenarla. Aunque las relaciones entre ambas esferas, la ética y la política, no le parecían de fácil armonización, se resistía a escindirlas o a ver necesariamente en ellas una relación trágica, frente a la que mantuvo la posibilidad de una tensión dramática, rechazando tanto la política carente de principios como la ética del alma bellan, que preserva su pureza a costa de la inoperancia o la evasión. Sin entrar en todos los desarrollos y propuestas que Aranguren lleva a cabo en esa obra (en la que, entre otros méritos, se hablaba, por primera vez entre nosotros, desde un punto de vista ético, de Max Weber, al que luego consagrarían excelentes trabajos profesores de diferentes generaciones, como, por ejemplo, Ignacio Sotelo o José María González), es preciso poner de relieve que al tema político le dedicó una atención cada vez mayor -de esa época es también su libro El marxismo como morah, 1.968-, unida al interés por la sociologia y las ciencias humanas, los movimientos sociales o la reflexión al hilo de las cambiantes circunstancias de la vida española. Bástenos destacar ahora que, frente a lo que a menudo sucede, Aranguren no escatimó sus críticas a lo que consideraba injusto del sistema social y político que le tocó vivir, no ya cuando carecía de reconocimiento público - entonces siempre es más fácil no venderse-, sino precisamente cuando lo adquirió. Su radicalización creció con los años en vez de buscar el acomodo a que el peso de los mismos tantas veces incita. Una radicalización que, por lo demás, supo no jactarse de sí, sino que acertó a acompañar la seriedad de sus posiciones con la ironía y el humor que impiden el envaramiento. Ello le permitió mostrar que el carácter moral - sobre el que asimismo reflexionó en tantas ocasiones-, no

B E. BONETE, Aranguren: la ética entre la religión y la politica, prólogo de J. Muguerza, Madrid, Tecnos, 1.989. 
tiene por qué ser equivalente de rigidez, de acartonamiento, de una actitud congelada, que, en el repliegue sobre sí, se desentiende del curso de los acontecimientos y es incapaz de interesarse por nada nuevo, pues en todas partes sólo encuentra el reflejo de su propia mueca.

En todo caso, esa actitud vigilante y crítica no sólo le había llevado en 1.965 a ser expulsado de su cátedra por la dictadura franquista, sino que también le condujo - tras su exilio americano en la Universidad de California y el posterior retorno a su cátedra española, en los comienzos de la transición democrática - a no darse por contento con la democracia recién inaugurada en nuestro país, sino, aun celebrándola, insistir en la diferencia entre la democracia establecida y la democracia como moral ${ }^{14}$, que es algo a conseguir cada día, sin que sea concebible un estado o situación en el que pudiéramos definitivamente descansar, como sobre algo poseído de una vez por todas. De ahí un impulso utópico al que, en ningún caso, podríamos renunciar sin abdicar a un tiempo de nosotros mismos.

De este modo, más allá del ámbito estrictamente académico, Aranguren ejerció un notable influjo sobre extensos sectores de la sociedad española. Siempre dispuesto a participar en un debate, en una mesa redonda, en conferencias de temas muy diversos; escribiendo comentarios de libros y prologándolos, dejándose entrevistar, sabiendo escuchar y tener una palabra oportuna, encarnó ejemplarmente el papel del intelectual, que él mismo, sin embargo, veía declinar, para dejar paso a lo que denominaba intelectual colectivom. Aranguren nunca se colocó au dessus de la mêlée, sino que supo realizar la tarea - bastante más ardua, como advertía Mairena - de estar a la altura de las circunstancias, por no andar de vuelta se permitió el lujo de recorrer y desbrozar un buen trecho de muchos caminos; la ironía y la distancia de sí le acercaron críticamente al mundo. En sus últimos años repitió, en diversas ocasiones, que aunque se sabía viejo no se sentía tal. Quizá su inusual juventud, intelectual y vital, se debiera en parte a saber conservar algo del infantil espíritu de asombro, de juego, de broma, que le curó del infantilismo de jugar a ser persona. Lo que, dicho sea de paso, le facilitó realmente serlo.

La breve presentación que acabo de realizar puede dar una idea del inmenso legado que, con su testimonio y su obra, José Luis López Aranguren

14 Cf. La democracia establecida: una crtica intelectual, Madrid, Taurus, 1.979. 
nos ha dejado. Y aunque no cabe duda de que será difícil hacerse cargo de él, es tarea nuestra recogerlo $y$, sin mimetismos que él sería el primero en repudiar, elaborarlo, como en buena medida algunos profesores e instituciones españolas están llevando a cabo. Quizá eso sea un buen síntoma, si significa que el diagnóstico de Ortega, según el cual los españoles no podemos permitir que alguien nuestro destaque, empieza a ser erróneo. Así parece mostrarlo la pluralidad de intereses, ámbitos de trabajo y corrientes que, al menos por lo que a la ética se refiere, se vienen cultivando en España. De esa pluralidad da buena cuenta la nutrida lista de colaboradores - entre los que me cupo contar - al volumen Etica dia tras dia. Homenaje al profesor Aranguren en su ochenta cumpleaños, editado por Trotta y dirigido por Javier Muguerza, Fernando Quesada y Roberto Rodríguez Aramayo ${ }^{15}$. Entre ellos figuran nombres tan conocidos como los de Saturnino Alvarez Turienzo, Feliciano Blázquez, Gabriel Bello, Domingo Blanco, Victoria Camps, Adela Cortina, Elías Díaz, Eusebio Fernández, Manuel Fraijo, Antonio GarcíaSantesmases, José Gómez Caffarena, José María Gómez Heras, José María González García, José Jiménez, Emilio Lledó, Ana Lucas, Manuel Reyes Mate, José Montoya, José Enrique Rodríguez Ibáñez, Xavier Rubert de Ventós, José Rubio Carracedo, Javier Sádaba, Fernando Savater, Carlos Thiebaut, Amelia Valcárcel, José María Valverde o Gerard Vilar. Y todo el que, de un modo más o menos directo, se dedica a la Etica en España reconoce su deuda para con Aranguren, tanto más fácil de llevar -aunque eso no quiere decir que sea menos exigente- por cuanto esa deuda, en vez de merma en la propia independencia, incita a ella y a pensar por cuenta propia. Y es que, como en cierta ocasión recordó Javier Muguerza al comentar la pluralidad de corrientes de la ética española actual a la que antes nos referíamos, sen el origen de esas rutas que discurren por suelo firme y entre amenos suburbios urbanizados, no hay que olvidar que estuvo un día una carretera polvorienta por la que apenas nadie osaba aventurarse para cruzar trechos y trechos de desérticas parameras. Que se sepa, Aranguren fue el primero en recorrerla a partir de la década de los cincuenta, teniendo durante mucho tiempo que hacerlo solo. $Y$ con ese largo viaje en solitario nos ensenó el camino a todos" ${ }^{16}$.

is J. Muguerza, F. Quesada, R. Rodriguez Aramayo, Etica dia tras día. Homenaje al profesor Aranguren en su ochenta cumpleaños, Madrid, Trotta, 1.991.

16 J. MuguerzA, "El largo viaje ético de Aranguren», El Pats, 4 de marzo de 1.995, 9-10. 
No querría terminar sin ceder la voz al propio Aranguren -aunque sea a través de la mía, que muy gustoso se la presto, en el sobreentendido de que no le desagradaría del todo-. Se trata de un texto, que quizá muchos de ustedes conozcan, pero que estimo no es inútil recordar un poco por extenso, como símbolo de la viveza de páginas que fueron escritas hace más de cuarenta años. Con él me enfrenté hace más de veinte, cuando era estudiante en la Facultad de Filosofía y todavía hoy, como entonces, sigue dándome qué pensar. Pertenece a su Etica y en él, además de un tema central de inspiración aristotélica, como el de la estructura circular del carácter, los hábitos y los actos, Aranguren retoma otros de raíz existencialista para hablarnos de los actos privilegiados, definitorios, pero no definitivos, pues el único momento definitivo es el de la muerte sobre el que él mismo tanto reflexionó, ofreciendo muy bellas páginas. Y dice así:

¿Los actos privilegiados en cuanto a la profundidad y reasunción que en ellos se alcanza son el instante, la repetición y el siempre. El concepto de los dos primeros fue forjado por Kierkegaard y desarrollado luego por Jaspers y por Heidegger. El siempre se debe a Xavier Zubiri. El acto privilegiado desde el punto de vista del kairós es la bora de la muerter.

El instante» es un acto momentáneo que, levántandose sobre la sucesión temporal, toca la trascendencia y tal vez la decide. Es la eternidad en el tiempo, tangencia de lo eterno y lo histórico, descenso de la infinitud a la existencia finita y elevación de ésta a aquélla en un golpe de vista» decisivo, echado desde la profundidad de un "presente auténtico". El instante puede revestir distintas formas. Una de ellas, la más alta, es el éxtasis, la contemplación mística. Pero sin necesidad de fenómenos místicos el hombre puede percatarse, de pronto, de la tremenda seriedad de su existencia y yelegirse». Desde el punto de vista del «contenido", en el que por ahora nos vedamos entrar, el sinstante» lo mismo puede ser un acontecimiento religioso que religioso-moral o puramente moral, lo mismo puede ser «unión" que «revelación», «aceptación» o conversión". El hombre se convierte a Dios siempre, como San Pablo, en un sinstante», aunque este instante" haya sido preparado por años, o aunque la expresión exterior y las consecuencias de esta conversión no se manifiesten sino mucho tiempo después. El ànstante» puede presentarse bajo la disposición anímica de la rangustia", como dicen Kierkegaard y Heidegger, pero no es nece- 
sario, ni mucho menos, que así sea. También, en otros casos, bajo la forma de «rapto", serenidad", splenitud", (paz".

El acto de la "repetición" consiste en la asunción, también en un instante, de la totalidad de la vida. Esta es, por decirlo así, tomada en peso y aceptada en su grandeza y en su miseria. Dicen que quien va a morir recorre en un momento todo su decurso temporal y we" su sentido. En esta concentrada actualización de la totalidad del pasado consiste precisamente la erepetición": el hombre «repite", vuelve a vivir en un instante», junta y apretada, su vida. La "repite", no como espectador, sino como su autor responsable. Desde el punto de vista del contenido" este acto puede consistir en arrepentimiento". Mejor dicho, y por aceptante" que sea, aunque suscriba la vida con un gran "sí", es también, necesariamente, sarrepentimiento", porque ¿quién no tiene de qué arrepentirse?. Como se ve, así como el instante" ahonda en el presente - frente al vivir en el superficial, disipado y atomizante ahora»- abriendo desde él el porvenir, la «repetición» vuelve la vista atrás, asume y retiene lo sido, frente al colvido" del pasado.

Xavier Zubiri ve la esencial forma del tiempo y su unidad, no en el instante» y la "repetición", como Kierkegaard, tampoco en la smemoria", como Bergson, sino en el siempre». El usiempre», el ade una vez por todas", es el fundamento de la mutación temporal, y el ahondamiento, la intensión en él otorga la posesión de sí mismo. El hombre está ante el decurso y su tiempo consiste en estar ante su propia decurrencia, autopresente a ella, incurso en ella, sí, pero también sobre ella (sobre la ifluencia» de Leclercq) y sobre sí mismo [...].

Pero estos actos - actualizaciones de estructuras, mejor-, el instantem, la "repetición", el ssiempre", son privilegiados y aun decisorios, definitorios, como dice Zubiri, pero no definitivos. El acto definitivo - no actualización de estructura, sino acto propiamente dicho, que, si lo es de verdad, será también unstante", "repetición" y ssiempre»- es la shora de la muerte». Pero en la shora de la muerten hay que distinguir, a mi parecer, dos aspectos: lo que tiene de suceso -el morir - y lo que tiene de acto humano, de última instancia concedida al hombre para la obra moral de sí mismo. Es importante distinguir estos dos aspectos, porque puede $-y$ probablemente suelen - presentarse disociados. El instante de la muerte biológica, según muestra la experiencia de la muerte ajena - experiencia, como tal, muy precaria y exterior"- sobreviene con frecuencia retrasado", cuando ya el hombre no se posee y lo que queda de él no es sino un residuo inconsciente y comatoso. El padre Karl Rahner ha 
llamado al último acto en que todavía disponemos de nosotros mismos la umuerte libre", a diferencia de la umuerte biológica". Ahora bien, desde el punto de vista que ahora estamos tratando -el de los actos privilegiadoseste es el acto definitivo. Hasta él «habla tiempo". El hombre conservaba ante sí algunas - muchas o pocas- posibilidades de modificar su êthos. Desde este instante, el êthos va a quedar definido y terminado, las posibilidades van a quedar fijadas para siempre, agotadas en el ser, coincidentes con él; empezamos a ser, definitivamente, lo que hemos hecho de nosotros mismos, lo que hemos querido ser [...].

Lo que importaba hacer ver en la presente reflexión sobre el objeto material, desde el punto de vista de su mera estructura, es que este objeto material consiste fundamentalmente en el êthos, esto es, en la personalidad moral; pero que la personalidad moral se define a través de todos y cada uno de los actos y de los hábitos, por lo cual éstos no pueden ser relegados a un segundo término al hablar del objeto de la ética. También, es verdad, a través de la vida entera. Pero, en primer lugar, la vida no es posible tenerla toda junta vivencialmente (realmente sí, porque queda impresa en nosotros; es, precisamente, nuestro "carácter", nuestro êthos), porque transcurre y se distiende en el tiempo. $\mathrm{O}$, mejor dicho: sí es posible tenerla toda junta, pero esto acontece precisamente en ciertos actos privilegiados. La vida como totalidad nos remite, pues, otra vez, a los actos que la resumen -el instante», la «repetición", el "siempre" (con lo cual se confirma una vez más la estructura circular del objeto de la ética: la totalidad remite a determinados actos, a través de los cuales se descubre precisamente aquel sentido total) - y al "carácter» en que queda «impresa». Y en segundo lugar, al hablar de la vida en su totalidad no debe olvidarse que ésta no es sólo duración, sino también futurición y emplazamiento. En el tiempo como futurición proyectamos el destino moral que vamos a forjar. En el tiempo como emplazamiento, y umientras llega la muerte», estamos a tiempo de rehacer ese destino moral [...].

La perfección ética ha de hacerse en el tiempo y con el tiempo. Nuestros proyectos se forjan en el tiempo, la perfección es cualitativamente diferente a lo largo de los años, la «experiencia de la vida» es experiencia del tiempo vivido. El concepto de kairós, u oportunidad, la eukairia o momento propio, es esencial para la tarea moral. Hay que dar tiempo al tiempo, saber esperar, aprovechar el cumplimiento de todas las condiciones, la realización de todas las posibilidades previamente necesarias, aprovechar el «ahora!». Y junto al concepto helénico del kairós, el concepto bíblico del pléroma. Cristo llegó a ssu hora", en la splenitud 
de los tiempos". Pero también, más modestamente, cada uno de nosotros tiene "su hora" y su "plenitud" para cada una de las partes de su tarea moral. El êthos se va forjando a través de los sucesivos kairoi, realizando cada cosa a su tiempo", sin que se pueda saltar por encima de él. De tal modo que la perfección es cualitativamente distinta no sólo para cada persona, sino también en cada kairós. Por eso la perfección del niño - abertura a la realidad, ojos abiertos ante el mundo, docilidad para lo superior- es cualitativamente diferente de la perfección del joven -entusiasmo, aspiraciones infinitas-, de la perfección del hombre maduro - -sentido de lo posible y de que la spaciencia es todon- y de la perfección del viejo - bendición universal, decir una gran sí de arrepentimiento, aceptación y fidelidad a cuanto se ha sido. La perfección ha de lograrse al hilo del tiempo, sin «adelantarse" y por eso son insatisfactorios el «niño prodigio" y también el niño empollón", que sofoca al niño auténtico, que tendría que haber sido para, a su tiempo, ser verdaderamente hombre. Hay una tarea moral para cada una de nuestras horas y la tarea moral, el êthos, tiene también su tiempo bien determinado, sus idías contados». En esto decía Séneca que nos diferenciamos de los dioses: en que se nos ha dado un tiempo finito. Por lo mismo es más precioso, tenemos que aprovecharlo ${ }^{\nabla}$.

Hasta aquí el texto de Aranguren, que les quería recordar. Tras su lectura, y con independencia de los acuerdos o desacuerdos que aquí o allá se pudieran mantener, no creo difícil ver en esos textos una filosofía que no está hecha de espaldas a la vida, ni por encima de de la vida; mucho menos, contra ella. Sino, más bien, desde la vida misma, para pensarla y acompañarla. Interrelación de vida y reflexión, de acción y discurso, que, como tuvimos ocasión de ver, el propio Aranguren se encargó explícitamente en tematizar. Quizá porque, aun siendo cierto, como quería el gran Goethe, que frente al frondoso y verde árbol de la vida, toda teoría puede resultar gris, también es verdad - según nos advierte desde lejos, pero no menos poderosamente, el viejo Platón-, que una vida no pensada no merece la pena de ser vivida. No cabe duda de que José Luis Aranguren fue capaz de vivir con intensidad la suya propia, porque también fue capaz de pensarla. Y pensando la suya y las cambiantes circunstancias en las que hubo de desarrollarse nos ayudó a todos los demás a pensar la nuestra propia, incitándonos a que no sólo la tengamos como un bien mostrenco, sino que acertemos a vivirla del modo más humano posible, a vivirla mejor.

17 J. L. L. ARANGUREN, Etica, en Obras completas. II, ed. cit., 1.994, 311-316. 